\title{
Inhibitory Effect of Japanese Green Tea Extracts on Growth of Canine Oral Bacteria
}

\author{
Emiko Isogar, ${ }^{1 *}$ Hirosni Isogar, ${ }^{2}$ Nobuhiro FujII, ${ }^{3}$ Koichi KImUra, ${ }^{3}$ \\ Hiroko Miura, ${ }^{1}$ Masanobu Hayashi, ${ }^{4}$ Shigeo Namioka, ${ }^{4}$ \\ Masayoshi KAWASAKI ${ }^{5}$ and Kunihiko IKEDA ${ }^{6}$ \\ ${ }^{1}$ Department of Preventive Dentistry, School of Dentistry, Higashi Nippon Gakuen University, \\ Ishikari-Tobetsu 1757, Hokkaido 061-02, \\ ${ }^{2}$ Division of Animal Experimentation, and ${ }^{3}$ Department of Microbiology, \\ Sapporo Medical College, Sapporo 060, \\ ${ }^{4}$ Department of Laboratory Animal Science, Faculty of Veterinary Medicine, \\ Hokkaido University, Sapporo 060, \\ ${ }^{5}$ Nissin Koryo Company Ltd., Nishitenman 4-3-12, Kita-ku, Osaka 530 and \\ ${ }^{6}$ Nippon Mining Company Ltd., Toranomon 2-10-1, Minato-ku, Tokyo 105
}

(Received for publication, March 9, 1992)

\begin{abstract}
The ethanol extracts from Japanese green tea from the leaf of Camellia sinensis (Japanese green tea) contained polyphenol compounds as major components. By liquid and gas chromatographic analysis, 5 catechin compounds were detected. The tea extracts (Deochon 13189-B, Deochon $30 \mathrm{EX}$ and Camellia $50 \mathrm{EX}$ ) were found to effectively inhibit the growth of canine oral bacteria. Minimum inhibitory concentration (MIC) was different among genus, species and strains of the bacteria. Canine periodontal pathogens such as Porphyromonas assacharolytica were sensitive to the tea extracts. Similar result was obtained by using human oral bacteria including periodontal pathogens. These results suggest that the tea extracts would be useful as anti-periodontitis agent and/or flora control agent in dogs.
\end{abstract}

Key words: green tea; polyphenolic compounds; oral flora; periodontitis; dog

It has been reported that oral disorders, especially periodontitis, are frequently found in $\operatorname{dogs}(5,11)$. The disease in dogs occurred with plaque accumulation and subsequent gingivitis, calculus formation and bone resorption with aging. Porphyromonas $(P$.$) asaccharolytica is a predominant isolate from adult periodontitis$ in dogs (4). With the increasing numbers of obligative anaerobic Gram-negative bacteria, the development of gingival inflammation was observed.

In man, many approaches have been adopted to prevent periodontitis after taking various factors into consideration. These approaches include the elimination of periodontal pathogens, enhancement of host defence, and modification of the diet $(9,11)$. However, no method for achieving the complete prevention of 
periodontal disease has been established yet. Therefore, methods which provide individuals with multiple preventive measures against the respective factors may be the most effective.

Japanese green tea contains polyphenolic compounds such as tannins (13). Tannins exist naturally in plants, and they possess potentially valuable anticariogenic abilities, including inhibition of bacterial growth $(2,13)$ and glucan synthesis $(7,10)$. Furthermore, they can reduce caries development in experimental animals (10). Japanese green tea leaves inhibited the growth of various bacteria causing diarrheal disease (12). The present study investigated the bactericidal effect of polyphenolic compounds from Japanese green tea on periodontal pathogens and oral bacteria in dog.

\section{MATERIALS AND METHODS}

Polyphenolic compounds from Japanese green tea. Deochon 13189-B, Deochon 30 EX and Camellia $50 \mathrm{EX}$ were originally isolated from the leaf of Camellia sinensis, known as Japanese green tea, by extraction using $95 \%$ ethanol $\left(80^{\circ} \mathrm{C}\right.$ for $\left.4 \mathrm{hr}\right)$. Extracted samples were filtrated by Toyo Roshi No. 2 (Toyo Roshi Co. Ltd., Japan) and lyophilized. The lyophilized sample was named as Deochon EX and suspended in $64 \%$ ethanol solution ( $300 \mathrm{mg} / \mathrm{ml}$, Deochon $30 \mathrm{EX}$ ). Deochon $30 \mathrm{EX}$ was diluted by distilled water and the concentration of the extract was adjusted at $60 \mathrm{mg} / \mathrm{ml}$ (Deochon 13189-B). Deochon 13189-B was treated with 15\% activated charcoal, filtrated through Kyuno No. 10S (Kyuno Co. Ltd., Japan), and lyophilized (Camellia EX). Camellia EX was suspended in distilled water $(500 \mathrm{mg} / \mathrm{ml}$, Camellia $50 \mathrm{EX})$. Deochon EX and Camellia EX were analyzed for the composition by high-performance liquid chromatography (Twinkle, Nihon Bunko Co. Ltd., Japan) and gas chromatography (GC-7A, Shimadzu Co. Ltd., Japan).

Bacteria. $P$. assacharolytica INU-1, INU-2, Prevotella (P.) intermedia INU-B4, $P$. melaninogenica INU-BL1, Fusobacterium $(F$.) nucleatum INU-F2, Lactobacillus $(L$.) acidophilus INU-L3, Lactobacillus spp. INU-LX, Streptococcus spp. INU-SSA1, INU7A3, INU-8SO1, INU-9SOA3, INU-2SOA2, originally isolated from dog oral cavity, were used (4). $P$. gingivalis HI-2, $P$. intermedia HI-20, Propionibacterium ( $P$.) acnes HI-101, Klebsiella $(K$.$) pneumonia HI-40, originally isolated from human oral$ cavity, were also used. P. gingivalis 381, ATCC 33277, P. intermedia NCTC 9336, $P$. melaninogenica ATCC 25845, P. loesheii ATCC 15930, P. levii VPI 10450, P. oralis VPI 7570, F. nucleatum IID 891, L. acidophilus IID 893, Staphylococcus (S.) aureus Cowan I were also used.

Minimum inhibitory concentration $(M I C)$. Determination of MIC was done by the standard method (3). Briefly, bacteria with 2 exceptions were grown in GAM broth (Nissui Co. Ltd., Japan) at $35^{\circ} \mathrm{C}$ for 24 to $48 \mathrm{hr}$ anaerobically $\left(\mathrm{N}_{2}: 80 \%\right.$; $\left.\mathrm{H}_{2}: 10 \% ; \mathrm{CO}_{2}: 10 \%\right)$. S. aureus and $K$. pneumonia were grown in brain heart infusion broth (BHI medium, Nissui Co. Ltd.) at $35^{\circ} \mathrm{C}$ for $24 \mathrm{hr}$ aerobically. Bacteria were suspended in the same media at the concentration of $10^{6} / \mathrm{ml}$ and $10^{8} / \mathrm{ml}$ respectively. GAM agar (Nissui Co. Ltd.) for anaerobic bacteria and BHI 
agar (Nissui Co. Ltd.) for aerobic bacteria were used for determination of MIC. The green tea extracts were added to the agar media at concentrations of 0.0015 to $6.4 \mathrm{mg} / \mathrm{ml}$ (2-fold dilution). One spot $(10 \mu \mathrm{l})$ of each bacterial solution was inoculated on the agar. After 24 to $48 \mathrm{hr}$ incubation, MIC was determined.

\section{RESULTS}

\section{Analysis of Tea Extracts}

As shown in Table 1, green tea extracts Deochon EX and Camellia EX included various components. Tannins were the major components of both extracts. Chlorophyll and lipids were removed by the treatment of activated charcoal. By the analysis of high-performance liquid chromatography of Camellia EX, the compounds contained five major polyphenolic compounds: (-)-epigallocatechin gallate, (-)-epigallocatechin, (-)-epicatechin gallate, (-)-epicatechin, and $(+)$-catechin (Table 2). Flavonoids such as rutin were also detected in the Camellia EX (Table 3).

$M I C$

Two strains of $P$. assacharolytica isolated from the dog with periodontitis were sensitive to green tea extracts, especially Camellia 50 EX (Table 4). The tea extracts were effective to $P$. gingivalis which was of human origin and one of the periodontal pathogens. Various species of Prevotella were sensitive to green tea extract in various concentrations. F. nucleatum INU-2 isolated from a dog was

Table 1. Composition of green tea extracts

\begin{tabular}{lcc}
\hline \multirow{2}{*}{$\begin{array}{l}\text { Composition } \\
\text { of tea extract }\end{array}$} & \multicolumn{2}{c}{$\%$ of composition in } \\
\cline { 2 - 3 } & Deochon EX & Camellia EX \\
\hline Tannins & 34.8 & 41.6 \\
Chlorophyll & 0.57 & ND $\left.^{a}\right)$ \\
Chlorophyll a & 0.49 & ND \\
Chlorophyll b & 0.08 & ND \\
Carbohydrate & 12.2 & 21.8 \\
Lipids & 37.4 & 0.6 \\
Minerals & 1.3 & 2.6 \\
Nitrogenous components & 2.46 & 2.10 \\
Caffeine & 5.8 & 4.2 \\
\hline
\end{tabular}

a) ND: not detected.

Table 2. Analysis of tannins in Camellia EX

\begin{tabular}{|c|c|}
\hline Tannins & $\%$ of composition \\
\hline (-)-epigallocatechin gallate & 17.8 \\
\hline (-)-epigallocatechin & 11.8 \\
\hline (-)-epicatechin gallate & 4.2 \\
\hline (-)-epicatechin & 2.8 \\
\hline $\mathrm{D}-(+)$-catechin & 0.4 \\
\hline
\end{tabular}


Table 3. Analysis of flavonoids in Camellia EX

\begin{tabular}{lc}
\hline Flavonoids & $\begin{array}{c}\text { Total amount } \\
(\mathrm{mg} / \mathrm{l00} \mathrm{g})\end{array}$ \\
\hline Chemical compound & \\
Rutin & 43 \\
Hyperin & 16 \\
Isoquercitrin & 9 \\
Quercitrin & 2 \\
Myricetin & $\mathrm{ND} a)$ \\
Quercetin & $\mathrm{ND}$ \\
Aglucon hydrolyzed & \\
Myricetin & 40 \\
Quercetin & 150 \\
Quenphenol & 100 \\
\hline
\end{tabular}

a) ND: not detected.

Table 4. Minimum inhibitory concentration (MIC) of polyphenolic compounds from Japanese green tea to various oral bacteria from dogs and humans

(Inoculum size: $10^{6} / \mathrm{ml}, 10 \mu \mathrm{l}$ )

\begin{tabular}{|c|c|c|c|c|}
\hline \multirow[t]{2}{*}{ Bacteria used } & & \multicolumn{3}{|c|}{$\begin{array}{l}\text { MIC (mg/ml) } \\
\text { Polyphenolic compounds from Japanese green tea }\end{array}$} \\
\hline & & Deochon 13189-B & Deochon $30 \mathrm{EX}$ & Camellia $50 \mathrm{EX}$ \\
\hline Porphyromonas & INU-1 & 3.2 & 3.2 & 0.8 \\
\hline assacharolytica & INU-2 & 1.6 & 3.2 & 0.8 \\
\hline \multirow[t]{3}{*}{$P$. gingivalis } & 381 & 0.8 & 0.4 & 0.8 \\
\hline & ATCC 33277 & 0.4 & 0.4 & 0.4 \\
\hline & HI-2 & 0.8 & 0.8 & 0.2 \\
\hline \multirow[t]{3}{*}{ Prevotella intermedia } & INU-B4 & 0.1 & 0.1 & 0.1 \\
\hline & NCTC 9336 & 0.1 & 0.1 & 0.1 \\
\hline & HI-20 & 0.2 & 0.2 & 0.2 \\
\hline \multirow[t]{2}{*}{ P. melaninogenica } & INU-BL1 & 0.4 & 0.4 & 0.4 \\
\hline & ATCC 25845 & 0.025 & 0.025 & 0.025 \\
\hline P. loescheii & ATCC 15930 & 3.2 & 3.2 & 3.2 \\
\hline P. levii & VPI 10450 & 0.8 & 0.8 & 0.4 \\
\hline$P$. oralis & VPI 7570 & $>6.4$ & $>6.4$ & $>6.4$ \\
\hline \multirow[t]{2}{*}{ F. nucleatum } & INU-F2 & 1.6 & 1.6 & 1.6 \\
\hline & IID 891 & 6.4 & $>6.4$ & $>6.4$ \\
\hline \multirow[t]{2}{*}{ L. acidophilus } & INU-L3 & 1.6 & 1.6 & 1.6 \\
\hline & IID 893 & 0.8 & 0.8 & 1.6 \\
\hline Lactobacillus spp. & INU-LX & 0.8 & 0.8 & 0.8 \\
\hline \multirow[t]{5}{*}{ Streptococcus spp. } & INU-SSA1 & 0.4 & 0.4 & 0.4 \\
\hline & INU-7A3 & 0.1 & 0.1 & 0.1 \\
\hline & INU-8SO1 & 0.1 & 0.1 & 0.1 \\
\hline & INU-9SOA3 & 0.2 & 0.2 & 0.1 \\
\hline & INU-2SOA2 & 0.2 & 0.2 & 0.2 \\
\hline Propionibacterium acnes & HI-101 & $>6.4$ & $>6.4$ & $>6.4$ \\
\hline$K$. pneumonia & $\mathrm{HI}-40$ & $>6.4$ & $>6.4$ & $>6.4$ \\
\hline S. aureus & Cowan I & 3.2 & 6.4 & 6.4 \\
\hline
\end{tabular}


Table 5. Minimum inhibitory concentration (MIC) of polyphenolic compounds from Japanese green tea to various oral bacteria from dogs and humans

(Inoculum size : $10^{8} / \mathrm{ml}, 10 \mu \mathrm{l}$ )

\begin{tabular}{|c|c|c|c|c|}
\hline \multirow[t]{2}{*}{ Bacteria used } & & \multicolumn{3}{|c|}{$\begin{array}{l}\text { MIC (mg/ml) } \\
\text { Polyphenolic compounds from Japanese green tea }\end{array}$} \\
\hline & & Deochon 13189-B & Deochon $30 \mathrm{EX}$ & Camellia $50 \mathrm{EX}$ \\
\hline Porphyromonas & INU-1 & $>6.4$ & $>6.4$ & 3.2 \\
\hline assacharolytica & INU-2 & $>6.4$ & $>6.4$ & 3.2 \\
\hline \multirow[t]{3}{*}{$P$. gingivalis } & 381 & 3.2 & 3.2 & 1.6 \\
\hline & ATCC 33277 & 1.6 & 3.2 & 1.6 \\
\hline & $\mathrm{HI}-2$ & 6.4 & 6.4 & 0.8 \\
\hline \multirow[t]{3}{*}{ Prevotella intermedia } & INU-B4 & 0.8 & 0.8 & 0.8 \\
\hline & HI-20 & 1.6 & 1.6 & 1.6 \\
\hline & NCTC 9336 & 6.4 & 6.4 & 6.4 \\
\hline \multirow[t]{2}{*}{ P. melaninogenica } & INU-BL1 & 0.8 & 0.8 & 0.8 \\
\hline & ATCC 25845 & 0.1 & 0.1 & 0.1 \\
\hline P. loescheii & ATCC 15930 & $>6.4$ & $>6.4$ & $>6.4$ \\
\hline P. levii & VPI 10450 & $>6.4$ & $>6.4$ & 1.6 \\
\hline$P$. oralis & VPI 7570 & $>6.4$ & $>6.4$ & $>6.4$ \\
\hline \multirow[t]{2}{*}{ F. nucleatum } & INU-F2 & $>6.4$ & $>6.4$ & $>6.4$ \\
\hline & IID 891 & $>6.4$ & $>6.4$ & $>6.4$ \\
\hline \multirow[t]{2}{*}{ L. acidophilus } & INU-L3 & $>6.4$ & $>6.4$ & $>6.4$ \\
\hline & IID 893 & $>6.4$ & $>6.4$ & $>6.4$ \\
\hline Lactobacillus spp. & INU-LX & $>6.4$ & $>6.4$ & $>6.4$ \\
\hline \multirow[t]{5}{*}{ Streptococcus spp. } & INU-SSA1 & 3.2 & 6.4 & 6.4 \\
\hline & INU-7A3 & 1.6 & 1.6 & 0.4 \\
\hline & INU-8SO1 & 0.8 & 0.8 & 0.8 \\
\hline & INU-9SOA3 & 0.8 & 0.8 & 0.8 \\
\hline & INU-2SOA2 & 1.6 & 1.6 & 1.6 \\
\hline Propionibacterium acnes & HI-101 & $>6.4$ & $>6.4$ & $>6.4$ \\
\hline K. pneumonia & $\mathrm{HI}-40$ & $>6.4$ & $>6.4$ & $>6.4$ \\
\hline$S$. aureus & Cowan I & $>6.4$ & $>6.4$ & $>6.4$ \\
\hline
\end{tabular}

sensitive, while IID 891 was resistant. Lactobacillus was sensitive without relation to its origin. Significant growth inhibition of oral streptococci isolated from dog was seen at the concentrations of 0.1 to $0.4 \mathrm{mg} / \mathrm{ml}$. P. acnes and $K$. pneumonia were not susceptible to the green tea extracts. $S$. aureus was sensitive to the tea extract at concentrations of 3.2 to $6.4 \mathrm{mg} / \mathrm{ml}$; MIC was increased with larger number of bacteria (from $10^{6}$ to $10^{8} / \mathrm{ml}$ ) and some strains were resistant to the green tea extracts (Table 5).

\section{DISCUSSION}

The chemical investigation of the tea extract showed that it contained several polyphenolic compounds. It has been reported that the polyphenolic compounds inhibit the growth of Streptococcus mutans, a cariogenic bacterium in man; inhibitory activity of $(+)$-gallocatechin and $(-)$-epigallocatechin are stronger than $(+)$ - 
catchin and (-)-epicatechin; also (-)-epigallocatechin gallate is more active than (-)-epicatechin gallate (13). Sakanaka et al (13) have described that the presence of the three hydroxy moieties at $3^{\prime}, 4^{\prime}$, and $5^{\prime}$ on the $B$ ring in the catechin and epicatechin molecules strengthen the inhibitory activity. The tea extract in this study contained (-)-epigallocatechin and (-)-epigallocatechin gallate as two major compounds. Therefore, green tea extract could provide effective prevention of periodontitis in dogs.

The inhibitory activity of the polyphenolic compounds varied depending on the genus and species of oral bacteria. The minimum inhibitory concentrations (MIC) were from 0.025 to more than $6.4 \mathrm{mg} / \mathrm{ml}$. Growth of many bacteria was inhibited at the concentration 0.1 to $0.8 \mathrm{mg} / \mathrm{ml}$. These MICs were much higher than those of various antibiotics. However, it is noteworthy that a cup of green tea extract $(100 \mathrm{ml})$ usually contains 50 to $100 \mathrm{mg}$ of the polyphenols. Green tea extracts could reduce periodontitis in dogs, because it is possible to add the tea extract at the effective concentration into pet foods.

The green tea extract was effective to oral bacteria from human origin. This fact indicated that a custom of drinking green tea in man might relate to preventing periodontal disease.

The types of microorganisms which first colonize a virgin site are those which find that environment to be congenial and the food supply to be adequate (9). Experimentally, we have showed that the oral streptococci could be the initial colonizer of the plaque and then provide the anaerobic conditions (6). The tea extracts had growth inhibitory activity to oral streptococci in dogs. It may be important to prevent the plaque formation at the first step.

It has been reported that periodontal diseases are frequently found in dogs (5). The disease is considered, to some extent, as a diet-related disorder. A soft or minced diet favors rapid accumulation of dental plaque and calculus, which may result in periodontitis $(1,8)$. Soft pet food has come to be widely used for dogs in recent years. There is some room for further improvement of the pet food. The tea extract could be useful for prevention of periodontitis in dogs.

\section{REFERENCES}

(1) Burwasser, P., and T.J. Hill. 1939. The effect of hard and soft diets on the gingival tissues of dogs. J. Dent. Res. 18: 389-393.

(2) Elvin-Lewis, M., M. Vitale, and T. Kopjas. 1980. Anticariogenic potential of commercial teas. J. Prev. Dent. 6: 273-284.

(3) Goto, S., K. Jo, T. Kawakita, N. Kosakai, S. Mitsuhashi, T. Nishino, N. Ohsawa, and H. Tanami. 1981. Improvement of test for minimum inhibitory concentration (MIC). Chemotherapy 29: 76-79 (in Japanese).

(4) Isogai, E., H. Isogai, H. Miura, K. Takano, Y. Aoi, M. Hayashi, and S. Namioka. 1989. Oral flora of mongrel and beagle dogs with periodontal disease. Jpn. J. Vet. Sci. 51: 110-118.

(5) Isogai, H., E. Isogai, H. Okamoto, H. Shirakawa, F. Nakamura, T. Matsumoto, T. Watanabe, H. Miura, Y. Aoi, W. Kagota, and K. Takano. 1989. Epidemiological study on periodontal diseases and some other dental disorder in dogs. Jpn. J. Vet. Sci. 51: 1151-1162.

(6) Isogai, E., H. Isogai, H. Sawada, H. Kaneko, and N. Ito. 1985. Microbial ecology of plaque in rats with naturally occurring gingivitis. Infect. Immun. 48: 520-527. 
(7) Kashket, S., V.J. Paolino, D. Lewis, and J. Van Houte. 1985. Glucosyltransferase inhibition by tannin-like constituents of beverages. J. Dent. Res. 64: 212.

(8) Krasse, B., and N. Brill. 1960. Effect of consistency of diet on bacteria on gingival pocket in dogs. Odont. Revy 11 : 152-165.

(9) Mergenhagen, S.E., and B. Rosan. 1985. Molecular basis of oral microbial adhesion. Am. Soc. for Microbiol., Washington.

(10) Otake, S., M. Makimura, T. Kuroki, Y. Nishihara, and M. Hirasawa. 1991. Anticaries effect of polyphenolic compounds from Japanese green tea. Caries Res. 25: 438-443.

(11) Page, R.C., and H.E. Schroeder. 1982. Periodontitis in man and other animals. A comparative review, Karger, Basel.

(12) Toda, M., S. Okubo, R. Ohnishi, and T. Shimamura. 1989. Antibacterial and bactericidal activities of Japanese green tea. Jpn. J. Bacteriol. 44: 669-672.

(13) Sakanaka, S., M. Kim, M. Taniguchi, and T. Yamamoto. 1989. Antibacterial substances in Japanese green tea extract against Streptococcus mutans, a cariovenic bacterium. Agric. Biol. Chem. 53: 2307-2311. 